\title{
O MITO DO ELDORADO: ORIGEM E SIGNIFICADO NO IMAGINÁRIO SUL-AMERICANO (SÉCULO XVI)
}

\author{
Johnni Langer*
}

RESUMO: O artigo trata da origem histórica do Eldorado e do seu significado para a mentalidade da época. Procurase entender como símbolos de longa duração, mitos indígenas e a epopéia colonialista articularam-se para formar a mais famosa cidade imaginária americana.

ABSTRACT: The article discusses the historical origin of Eldorado and its meaning for the mentality of that epoch. It also intends to understand how long duration symbols, indigenous myths and the colonial epopee articulated with each other to criate the most famous imaginary american city.

PALAVRAS-CHAVE: Cidades imaginárias, mitos americanos, mentalidade.

KEYWORDS: Imaginary cities, american myths, mentality.

Na história da colonização e exploração americana, o mito ${ }^{1}$ das cidades de ouro (principalmente o Eldorado) sempre teve grande repercussão e importância. Como simples fantasias puderam por tanto tempo sobreviver na credulidade ocidental? Qual o verdadeiro significado desse mito para a mentalidade da época? A maioria dos historiadores e das pes-

\footnotetext{
* Doutorando em História - Universidade Federal do Paraná.

${ }^{1} \mathrm{O}$ mito, segundo Raoul Girardet, é uma metamorfose da recusa do real, que fornece uma explicação dos acontecimentos e fatos, realizando um papel de mobilização social (GIRARDET, 1987. p.13). Segundo Bronislaw Baczo, o mito é uma produção do
}

quisas sobre esse tema, concebem-no como uma simples ficção. A mais conhecida e divulgada teoria, considera o Eldorado uma invenção puramente indígena, criada com o propósito de ludibriar os gananciosos europeus (NOUHAD, 1988). Outra, de tendência recente, argumenta que este mito foi concebido pelos espanhóis para ocultar o massacre autóctone,

imaginário social que fornece respostas à própria sociedade de "seus desequilíbrios às tensões no interior das estruturas sociais e às eventuais ameaças de violência" (BACZO, 1984, p.308). E segundo Cornelius Castoriadis o mito é "uma respostas racional dada no imaginário por meios simbólicos” (CASTORIADIS, 1982). 
servindo na prática para esconder o preço em vidas indígenas da expropriação da terra e de seus minerais preciosos. Ou ainda, de que teria sido formulado apenas pelo pensamento europeu, não recebendo influências indígenas (RAMOS PÉREZ, 1995, p. 281). Ambas as considerações são limitadas, pois não concebem o mito em seus aspectos literários, dentro do contexto da mentalidade do período, e mesmo suas matrizes culturais pelo imaginário, que já existiam antes mesmo da descoberta do Novo Mundo.

Podemos considerar o mito do Eldorado em duas perspectivas básicas, independentes e ao mesmo tempo intrínsecas: as expedições de busca e as narrativas documentais. A primeira foi influenciada principalmente por motivos simbólicos da mentalidade européia (entre os quais o velocino de ouro), enquanto que as narrativas foram estabelecidas em evidências históricas (cultos indígenas) em confluência intrínseca com mitos europeus. É evidente que em diversas ocasiões ambas as perspectivas fundiram-se, e muitas expedições eram organizadas a partir da popularização de relações impressas. Mas as simbolizações do ouro e a sua busca já estavam presentes antes mesmo da formação histórica do mito do Eldorado.

\section{As matrizes culturais do mito}

Desde os primórdios da descoberta e colonização das Américas, a esperança de enriquecimento rápido constituiu um dos fatores básicos de motivação das expedições, em meio as incertezas de locais misteriosos e desconhecidos. O maravilhoso ${ }^{2}$, baseado em narrativas reais e imaginárias, transportou para o Novo

2. O maravilhoso é todo imaginário que expressa as diferenciações culturais entre o autor, seu público e as descrições de um mundo distante, exótico e disforme, traduzidos em imagens fantásticas e estupendas (LANCIANNI, $\mathrm{n}^{\circ}$ 21, p.21). Abrangendo
Mundo diversas tradições ocidentais, algumas das quais relacionadas à riqueza e ao ouro. Para além do seu valor material, o ouro possuía um extraordinário encanto, pois é o símbolo da perfeição e da imortalidade (MARSON, 1992, p. 171). O mais nobre dos metais, utilizado como metáfora do poder político e da realeza, foi vinculado também a aspectos religiosos e místicos. O europeu, desta forma, herdeiro de um vasto repertório fantástico sobre esse metal, transferiu para o incógnito uma ambígua e extrema obsessão da busca pela riqueza e poder. O que leva historiadores como Guilherme Giucci a considerar a essência do maravilhoso americano como exclusivamente econômica (GIUCCI, 1992, p. 13).

O primeiro elemento fantástico das representações de riqueza na América foi a sua extrema abundância, pois para os europeus o ouro encontrava-se com facilidade em qualquer parte do Novo Mundo. Alguns cronistas do século XVI descreveram a existência de ouro aflorando fantasticamente na superfície da terra, crescendo como plantas e mesmo abundante como os peixes nos rios (LAS CASAS, 1951, p. 353). Desta forma, o recente e desconhecido continente descoberto possuía a capacidade de enriquecer o conquistador, seja pela sua abundância em riquezas metálicas, conseguidas com as ingênuas culturas ameríndias, como pela própria fartura da natureza - o meio assumiu a propriedade de transformar-se em um equivalente físico do país de Cocanha (a terra da fartura medieval).

Outro elemento fantástico relacionado ao ouro foram os simbolismos de sua procura. Vários pesquisadores já perceberam que o ímpeto de busca dos conquistadores espanhóis não se devia apenas ao caráter material do metal dourado, pois a cada nova

vários sistemas simbólicos (mitos e utopias), o maravilhoso privilegia as imagens de viagens e explorações ou descrições de contato com o outro, numa relação de alteridade. 
posse deste buscava-se outra. Como se a própria procura fosse mais importante que a aquisição em si: "Sobre esses homens rudes, o ouro exercia uma espécie de fascinação; mas logo que o possuíam quebrava-se o encanto" (HUBER, 1961, p. 183). A jornada pelo incógnito assume uma função simbólica, inicialmente mais importante que o acúmulo de riquezas materiais: "el espanhol ama más la aventura de buscar la riqueza que la especulacion econômica"(SALAS, 1967, p. 59). Mesmo entre os cronistas da época, também percebia-se essa tendência: isso aproxima o conquistador do aventureiro antigo, nos elementos que compõe a primeira matriz do Eldorado - a tradição do velocino de ouro, uma influência objetiva da mitologia grega no imaginário da conquista ${ }^{3}$

Várias características simbólicas sobressaem-se da narrativa clássica dos argonautas: o heroísmo, o navio, a viagem ao desconhecido e a conquista do tesouro oculto ${ }^{4}$. O heroísmo aqui destacado é a aventura coletiva, na qual o indivíduo tem importância secundária, manifestada diretamente com os conquistadores europeus do século XVI. O navio Argos simbolizou o fruto do mal, porque a navegação para os autores clássicos representava a perda da felicidade original : a imobilidade é o Paraíso e a curiosidade a transgressão (AINSA, 1986, p. 10). O velocino de ouro, por sua vez, simbolizou o ouro de conquista "que incorpora una dimen-

3. Cristovão Colombo, Estrabão, Toscanelli e Martin Behaim elaboraram seus projetos geográficos levando em conta os versos de Medea de Sêneca (AINSA, 1986, p.5). O cronista Lopes de Gomara também observou essa famosa obra de Sêneca como uma profecia da descoberta da América (GOMARA, 1965. p.368).

4. As aventuras de Jasão constituem a primeira aventura náutica do Ocidente que em seu núcleo primitivo - são anteriores à redação da Odisséia. A sua celebridade se deve a Apolônio de Rodes, que escreveu as Argonáuticas no terceiro século antes de Cristo (GRIMAL, 1965. p.51). sion de botin y tesoro a la sociedade igualitária de la época" (AINSA, 1986, p. 17), adquirido após a ultrapassagem de diversos obstáculos e perigos. Desta maneira, a busca do ouro simbólico - ou do velo de ouro americano - explicaria a atitude espanhola perante o desconhecido, somada à influência objetiva da literatura argonáutica, como a do Le livre du preux et vaillant Jason et de la belle Médée, publicado por Raul Lefévre poucos anos antes da descoberta do Novo Mundo (Paris, 1460).

Com a colonização da América, esses aspectos acentuaram-se cada vez mais. Mesmo após encontrarem fabulosas riquezas no mundo inca e asteca, além de inúmeras minas de ouro e prata, centenas de pessoas partem em busca de fantasiosos e miríficos reinos, pois na busca de riquezas "no se trata únicamente de su valor material, tal como podría ser evaluado hoy en día, lo que está en juego, sino el simbolo en que ese oro va encarnando a medida que el viaje progresa. El oro és una meta" (AINSA, 1986, p. 21). E também somado à essa influência simbólica, ocorreram elementos do imaginário cristão, observado por Buarque de Hollanda em uma ambiguiidade inicial, uma fusão entre o material e o espiritual nas expedições de conquista: "com aquela mescla de espiritualidade e riqueza, de devoção e ambição, de religião do Cristo e do culto do bezerro de ouro, que se acha à base da demanda obstinada" (HOLLANDA, 1985, p. 33).

Assim, o imaginário do maravilhoso relacionou a estranheza do remoto distante (a América) à nostalgia de um valor simbólico que devia ser recuperado. Aqui a viagem e a exploração, como demonstrou Giulia Lancianni, caracterizam-se como a "conquista do espaço de alteridade, como recuperação de mirabilias perdidas" (LANCIANNI, n 21 , p. 22), que inicialmente na busca dos tesouros americanos foi a recuperação do velocino de ouro e do desejo de combinar os valores alienígenas com o seu próprio sistema cultural, convertidos em uma 
só linguagem, a do maravilhoso. A viagem-exploração, deste modo, também é um processo simbólico do imaginário: "a busca do ouro mítico, como do ouro filosófico da Idade Média, supõe ritos iniciáticos, pontuados de sofrimentos e de sacrifícios incontornáveis, sem os quais o ouro permanecerá escondido" (NAVARRO, 1992, p. 148). Jacques Le Goff também considerou a viagem dentro desta perspectiva, na qual a aventura assume uma busca pela identidade individual - sendo ela própria uma maravilha (LE GOFF, 1985, p. 23).

Também é perceptível que a maior parte das fantasias e desejos de riqueza materializou-se com a conquista dos grandes impérios indígenas americanos, principalmente o asteca e incaico. A civilização asteca, dominada desde 1521, permitiu aos espanhóis perceberem que os habitantes destas regiões não conferiam nenhuma conotação econômica aos metais tão preciosos, apenas valores ritualísticos, o que lhes facilitava sua posse e conquista. E o império inca foi dominado em 1530. Com isso, as mais famosas descrições de cidades fantásticas americanas iniciam-se durante a década de 30 do século XVI: Sete cidades de Cibola (México e Texas) e Eldorado (América do Sul).

\section{A origem histórica do Eldorado}

A origem do Eldorado remonta a 1531-1532, quando o conquistador Diego de Ordaz foi informado sobre a existência do País de Meta, que seria rico em ouro e pedras preciosas ${ }^{5}$. Sua localização (entre o Peru e a Colômbia) foi influenciada pela cultura

5. O fabuloso e rico país de Meta, situado no rio de mesmo nome (no interior da Colômbia), com o tempo transformou-se no Eldorado: ambos tiveram em sua origem o contato dos espanhóis com a cultura Chibcha (RAMOS PÉREZ, 1954. p.20-54). pré-colombiana Chibcha - também denominada de Muisca. Logo depois, em 1534, Luiz de Daza encontrou no Equador um índio chamado Muequetá (ou Muiziquitá), que se dirigia ao rei de Quito para solicitar ajuda na guerra contra os Chibcha. Ao descrever o seu país, referiu-se pela primeira vez ao cacique que se banhava com ouro em uma lagoa. Sebastião de Becalcázar (ou Benalcázar), o fundador de Quito, foi um dos iniciadores da busca ao mítico personagem ${ }^{6}$. Para diferenciar este local de outras províncias espanholas, Becalcázar denominou-o de Província del Dorado em 1534. O primeiro relato impresso sobre o Eldorado foi de Gonçalo de Oviedo, em 1541 (História general y natural de las Índias). Segundo esse cronista, um príncipe indígena diariamente se cobria com uma espécie de resina, sobre a qual era aplicado ouro em pó por toda a extensão de seu corpo (ALÉS \& PUYLLAN, 1992, p. 287).

A repercussão desse depoimento para a mentalidade do período foi fundamental. Não se encontrou em nenhuma cultura indígena até aquele momento, uma utilização de riquezas de tal modo - característica de um raça muito rica e portadora de fabulosas riquezas. Essa tradição do homem dourado, advinda de informações indígenas, foi baseada em um culto religioso dos Chibcha (situados na Colômbia). Várias pesquisas arqueológicas atuais confirmam a autenticidade deste episódio, que desapareceu antes da conquista ${ }^{7}$.

6. As principais expedições em busca do Eldorado foram: Diego de Ordaz (1530), Sebastião de Benalcázar (1531-32), Antonio de Herrera (1535), Pedro de Candia (1535), Gonçalo Quesada (1537), Gonçalo Ximenes de Quesada (1539), Pizarro (1541-42), Pérez de Quesada (1540-42), Francisco de Orellana (1541-42), Phillip Von Hutten (1541-46), Lope de Aguirre (1552-60), Pedro de Ursua 91559), Antônio de Sepúlveda (1580), Antonio de Berrio (1584-95), Walter Raleigh (1595), Robert Harcourt (1613) e Apolinário Dias de Fuente (1760). (GANDIA, 1929. p. 103-143). 
Ainda em 1537, o general Gonzalo Quesada, e em 1580 Antônio Sepúlveda, retiraram imensas quantidades de objetos indígenas de ouro do lago Guatavita, sem saberem que era o local original do culto Chibcha, intensamente procurado. Mas a primeira ligação textual entre o homem dourado e um lago, ocorreu em 1542, com uma carta de Pizzaro ao rei espanhol (ALÉS \& POUYLLAN, 1992, p. 288).

Aos poucos, o Eldorado metamorfoseia-se no imaginário dos conquistadores, passando a designar primeiramente toda mina aurífera, posteriormente toda cidade e país inexplorado, no qual corria qualquer rumor de riqueza e mistério ${ }^{8}$. Isso explica-se por uma característica básica do maravilhoso, a sua relação com o remoto-desconhecido. Os símbolos do maravilhoso necessitam basicamente de um contexto fora do familiar para o receptor-leitor. Das primeiras viagens marítimas até a descoberta oficial da América, manifestaram-se diversas imagens de monstros e personagens bizarros em meio às novas e desconhecidas terras, transposições de mitos europeus ${ }^{9}$. Logo que expedições iniciaram o vislumbramento dos interiores, inóspitos mesmo aos indígenas civilizados, novamente o maravilhoso manifestou-se, elegendo as florestas tropicais (principalmen-

7. Na cultura Chibcha, os chefes viajavam em liteiras adornadas com ouro e feixes deste metal penduradas na porta do palácio. Cavernas, montanhas, lagos e templos eram considerados lugares sagrados onde os deuses recebiam ouro e esmeraldas. "A cerimônia que inflamou a imaginação dos soldados espanhóis, entretanto, era a praticada quando um novo chefe assumia o poder. Em tal ocasião, o iniciado era coberto com resina e envolto em ouro em pó. Fulgurante da cabeça aos pés, era levado em uma canoa ao centro da lagoa sagrada. Enquanto seus súditos lançavam da praia oferendas à agua, ele mergulhava para retirar o ouro, que permanecia no fundo do lago" (MEGGERS, 1985. p. 134). Apesar de especialistas modernos negarem a vinculação desse episódio indígena com o mito espanhol (RAMOS PÉREZ, 1995, p.281), a sua confirmação atual é um consenso entre os arqueólogos colombia- te a Amazônia) como locais privilegiados para a sua existência.

Entre 1540 e 1560, as descrições do Eldorado e de locais fantásticos começaram a somar-se às do Peru incaico. Reflexo disso foi a narrativa do padre Gaspar de Carvajal em 1541, que também constituiu uma transposição de elementos míticos da mentalidade européia. Na região próxima do Rio Negro (Amazonas), a expedição chefiada por Francisco de Orellana foi atacada por um grupo de mulheres guerreiras. Seguindo o curso, capturam um indígena, que lhes descreveu a cidade destas guerreiras: “(...) de piedra y con sus puertas, y que de un pueblo a otro iban caminos cercados de una parte y de otra y a trechos por ellos puertas donde estaban guardas para cobrar derechos de los que entran" (CARVAJAL, 1955, p. 104).

Acostumados a descobrir aldeias indígenas com estruturas rudimentares, a descrição imaginária de casas de pedra à maneira européia (como as do Peru incaico), era um importante indício de civilização para os padrões mentais do período. Ainda segundo Gaspar de Carvajal, na capital com muita riqueza em ouro e prata, haveria "cinco casas del sol a donde tienen sus ídolos de oro y de plata (...) y estos

nos e norte-americanos. O cacique de Guatavita (lago da Colômbia) mantinha um grande poder econômico e político em diversas regiões indígenas através do misterioso culto do encobrimento com ouro (FERNANDO PÉREZ, 1990, p. 03)

8. Apesar dessa transformação, a descrição do culto dourado permaneceu constante no imaginário. Entre 1570 e 1580 foi escrito o famoso livro de Juan de Castellanos, Elegias de varones ilustres de Indias (publicado em 1589), que divulgava em emocionantes versos as etapas do resplandecente ritual (FERNANDO PÉREZ, 1990, p. 06).

9. Os modelos imaginários são fundamentais para a compreensão desse mitos: "numa época em que ouvir valia mais do que ver, os olhos enxergavam primeiro o que se ouvira dizer"' (MELLO E SOUZA, 1986. p.21). 
adoratorios y casas ya dichas llaman los indios "carana" y "ochisemomuna", que quiere decir casas del sol" (CARVAJAL, 1955, p. 105). Lembrando a descrição de Francisco Xerez (impressa em 1534, sobre a Cuzco peruana): "Esta casa dicen que es del sol, porque en cada pueblo hacen sus mesquitas al sol" (HOLLANDA, 1985, p. 29). Tendo conhecimento da relação sol-ouro para os indígenas civilizados, os espanhóis associaram aos países imaginários a existência desses locais. Gaspar de Carvajal também descreveu o interior destas casas, com os tetos ornados com pinturas e objetos de ouro para culto ao sol. Relatou ainda camelos e ovelhas do Peru e "dos lagunas pequeñas de agua salgada, de que hacen sal" (CARVAJAL, 1955, p. 106). A descrição de mulheres guerreiras na América foi muito comum. Colombo mencionou a ilha das Amazonas em seus diários, Matininó, que constava na cartografia medieval desde o século XIII como a isle Femelle (GANDIA, 1929, p. 64).

Apesar da remota existência no passado da participação de mulheres guerreiras e de mitos ancestrais referentes ao matriarcado ${ }^{10}$, a transposição do imaginário europeu foi o elemento predominante nestas narrativas exploratórias. Membro da expedição que buscava o País da Canela, Carvajal descreveu um estado dominado por guerreiras que controlavam diversas aldeias vizinhas. Ao final do século XVI, essa relação é invertida, e o país das Amazonas torna-se protetorado do império do Eldorado.

10. Historiadores atuais do imaginário mítico da conquista, como Tânia Navarro, ainda insistem na veracidade do relato de Carvajal: "Nada prova que não existiram essas mulheres guerreiras (...) e a mistificação neste caso não passa de uma tentativa de obscurecimento em relação a uma realidade possível e indesejável ao sistema" (NAVARRO, 1992, p.161). Essas concepções esquecem que os europeus, antes de mais nada, vislumbravam no desconhecido imagens familiares ao seu referencial cultural, que eram integrantes de uma tradição secular. Assim, a imagem de uma soci-
Com a primeira edição impressa da obra História Geral de las Índias de Francisco Lopes de Gomara em 1552, a aproximação do Eldorado com o Peru foi ainda mais acentuada. O cronista descreveu em detalhes o resplandecer de Cuzco, a grande capital incaica no Peru, modelo andino para toda a América: todos os objetos domésticos e estatuária eram de ouro puro (GOMARA, 1965, p. 209).

As casas do sol, templos religiosos dos indígenas sul-americanos, transformaram-se em sinônimo de riqueza, pela associação entre o simbolismo do astro rei com a cor e o metal dourado, e frequientemente integram ou substituem as imagens literárias das cidades de ouro ${ }^{11}$. A substituição pretende tornar mais objetivos e reais os relatos sobre o mito - afinal, as Casas do Sol eram locais materialmente concretos e sua menção já evidenciava a própria transformação do Eldorado de cacique indígena para uma cidade. Um fato que ocorreu objetivamente no final do século XVI.

\section{Metamorfose do fantástico: a Relación de Martinez}

Aproximadamente entre os anos de 1580 a 1590, surgiu um manuscrito chamado Relación de Martinez, de grande influência no período. Nele, descreve-se as peripécias de Johannes Martines, mestre de

edade de mulheres guerreiras existiu desde os gregos, na cartografia medieval, na literatura fantástica do séc. XIV ao XVI, e nos relatos de explorações geográficas da Ásia e África. Não há evidências no passado histórico de uma tal sociedade, depois de um século de pesquisas arqueológicas na região amazônica.

11. O historiador argentino Enrique Gandia, ao analisar documentos coloniais, constatou essa associação. Escriturários de Assunção em 1601, ao transcreverem a Relación de Hernando de Ribeira (1543), trocaram as frases originais "Casa del Sol" por "Eldorado" e dicen que ali se enciera el sol por "que hasta la laguna llaman Eldorado" (GANDIA, 1929, p.204). 
munições de Diego de Ordaz em 1531, que foi abandonado por traição na floresta. Posteriormente familiarizou-se com os indígenas da região, que o levaram até à cidade dourada de Manoa, onde teria permanecido por sete meses. Depois de fugir do cativeiro, fez no leito de morte revelações a um confessor - originando o manuscrito ${ }^{12}$. Em 1595, o general Antonio de Berrio em sua relação impressa em Trinidad (influenciado por Martinez), utilizou-se do termo Manoa, deslocando o mito do Eldorado da Colômbia para a região entre a Venezuela e as Guianas.

Segundo Johannes Martinez, a fabulosa cidade seria situada entre uma montanha de ouro, de prata e de sal. O palácio do imperador, o principal edifício da cidade, foi localizado em uma verdejante ilha com um lago. A entrada seria sustentada por magníficas colunas de pórfiro e alabastro - simetricamente alinhadas - com uma galeria ornada por bois de ébano e jóias. Dentro do palácio destaca-se uma imensa coluna de 25 pés de altura, cujo capitel superior ostenta uma imensa lua de argento. Na base dessa coluna, dois leões vivos estavam presos por correntes de ouro maciço. E ainda no centro do edifício também estava localizada uma fonte quadrangular ornada com quatro tubos de ouro e um imenso sol com quatro lâmpadas de brilho perpétuo (Grand Dictionnaire du XIX siècle, 1871, p. 296).

Este relato sobre o Eldorado foi o primeiro que transpôs objetivamente elementos do imaginário eu-

12. Segundo alguns especialistas, esse manuscrito teria sido inventado pelo conquistador Domingo de Vera, para impressionar o general Antonio de Berrio - que publicou em 1593 uma relação com elementos da narrativa de Martinez: Relación de lo sucedido en el descubrimiento de guayana y Manoa. (GANDIA, 1929, p.132).

13. Apesar disso, o relato de Martinez ainda conservou a tradição do ritual dourado: "En suas fiestas, cuando el emperador brinda con sus capitanes y tributarios, entran los criados y untan el cuerpo de éstos con un bálsamo blanco que llaman Curcay, y ropeu, deslocando-se da matriz indígena do culto Chibcha ${ }^{13}$. Também pela primeira vez surge a denominação Manoa (Manoce), o termo supostamente usado pelos índios Achaga para a cidade de ouro cujo significado seria laguna ou lago (GIL, 1989). Além da fusão de elementos autóctones, Johannes Martinez acrescentou a descrição das riquezas de Cuzco, realizada em 1552 por Lopes de Gomara. Tudo é feito de ouro, desde as estruturas arquitetônicas até os objetos domésticos: a imagem de uma urbe acentua os referenciais de civilização e de riquezas.

Constituia-se a primeira narrativa definitiva do mito como cidade. A sua situação geográfica - situado em meio à uma verdejante ilha de um lago (já antevista por Gonçalo de Oviedo e Gaspar de Carvajal) - foi destacada por Johannes Martinez. Ainda que os mitos indígenas estivessem relacionados a lagos geograficamente reais - como o Guatavita (Colômbia) e o Titicaca (Peru) - a sucessiva conotação fantástica das descrições foi enriquecida pelo imaginário europeu. O fato do lago Parimá (também denominado de Rupunuwini) ser representado como salgado, reforçou a imagem do mar-oceano envolvendo a cidade dourada. Aqui temos definida outra matriz cultural do mito, a nostalgia da Idade de Ouro (de origem greco-romana) e do Paraíso Perdido (de origem judaico-cristã), ambas simbolicamente manifestadas com a alegoria da ilha.

luego soplan sobre ellos oro en polvo por medio de canãs huecas, hasta que quedan brilhantes de pies a cabeza, y asi adornados, se sientan y beben, por veintenas y centenas, por cinco o seis dias seguidos. Y por haber visto eso, y por la abundancia de oro que ví en la ciudad, las imagenes de oro que usam em sus guerras, llamó a quela region el Dorado" (GANDIA, op.cit., p.132). Observa-se que a descrição do culto é praticamente semelhante à narrativa efetuada por Oviedo em 1541, com exceção da afirmação de que Martinez teria presenciado pessoalmente o ritual. 
As representações de uma sociedade ideal e harmônica, sempre presente na história humana, tomou forma definida com os gregos ${ }^{14}$. Hesíodo (século VII a.C.) relatou a raça de ouro ancestral, e Ovídio (século I d.C.) difundiu a noção de aurea aetas da humanidade. Porém foi com Virgílio que se desenvolveu a concepção de um retorno a essa felicidade perdida, desterrada pelos deuses com a transgressão humana da navegação e da mobilidade geográfica. Ambiguamente, também é com a navegação que o homem pode reencontrar essa mirabilia, pois a Idade de Ouro permanece ainda incólume em ilhas perdidas e inacessíveis. Assim, na epopéia marítima da Odysséia (9 a.C.), Homero descreveu o encontro de Ulisses com ilhas onde não existem enfermidades e doenças aos mortais, entre as quais as Scylla, Ogígia e as famosas Afortunadas. Mais tarde Cícero e Plutarco (68-44 a.C.) popularizaram estes locais em seus escritos, como regiões incomuns de felicidade, onde a vida é facilitada pela ausência de sofrimento (MANGUEL, 1987, p. 134). Percebe-se aqui o clima ameno, que será constante nas descrições paradisíacas, mesmo no Brasil colonial, conforme demonstrou Buarque de Hollanda. Também identificada ao Horto das Delícias e ao jardim das Hespérides, a imagem tradicional das ilhas Afortunadas condensaram as narrativas da terra da abundância, da longevidade e da igualdade, manifestando-se mesmo na cartografia medieval até o século XVI. Outra famosa ilha foi a descrita por Platão, Atlantis (século 4 a.C.). Sua capital com palácios e riquezas sem fim, rivaliza com outras célebres ilhas gregas, como

14. Para Hollanda, as motivações paradisíacas tiveram origem psicossocial: "aquela condição de plena bem aventurança, tal como a viram e cantaram os poetas, representaria a projeção, sobre um plano cósmico, da vida da infância tal como o podem ver os adultos, isto é uma infância idealizada pela distância: assim, era natural que a situassem no passado”. (HOLLANDA, op.cit., p.146)
Hyperbórea e Thule, estabelecendo um importante referencial para a imagem das cidades imaginárias americanas. A Idade Média, dando sequiência à tradição, incorporou as narrativas gregas às celtas, cujo exemplo maior é a ilha de Avalon (século 13 d.C.). Merecem também destaque as ilhas de São Brandão, Brazil e Antilia. Com conotações místicas e sobrenaturais, elas originaram-se da cartografia e da literatura ente os séculos XIII e XV (HOLLANDA, 1985, p. 150)

A partir de fins do século XV, a Europa foi acometida de um grande retorno à mitologia clássica e a nostalgias perdidas, através da literatura, pintura, escultura e da poesia. Em parte pelas novas terras descobertas - que reavivaram esses símbolos enfraquecidos na mentalidade européia - e também pelas mudanças culturais efetuadas pelo renascimento clássico, que antecedeu a formação dos mitos americanos. Em 1487 foi publicado o romance Orlando Innamorato, de Matteo Maria Boiard, no qual é descrita a ilha do palácio de Joy, situada no Atlântico. Além das descrições do clima excepcional, o palácio é descrito como sustentado por colunas de cristal e telhados de ouro, com pavilhões incrustados de metais preciosos (MANGUEL, 1987, p. 185). Em especial essas descrições de arquitetura fabulosa são uma óbvia influência para as posteriores narrativas do Eldorado. Já no século XVI, na península Ibérica, iniciaramse diversos romances de cavalaria - muito populares entre os conquistadores espanhóis - com elementos do maravilhoso medieval, entre as quais a descrição de seres fantásticos, e mesmo da continuidade das narrativas de ilhas paradisíacas (HOLLANDA, 1985, p. 19).

Especialmente o Amadis de Gaula (Zaragoza, 1508), iniciou um ciclo de enorme influência nas letras ibéricas. Inspirada pelas novelas medievais, como as de Lancelot e Tristão, a aventura espiritual do cavaleiro ocorre em meio a toda uma série de pe- 
ripécias e aventuras fantásticas pelo desconhecido. Dos vários reinos fantásticos citados em meio a ilhas perdidas, o Amadís de Gaula descrevia em especial o do imperador Apolodium na Fixed Isle: em um ambiente paradisíaco e verdejante, diversas construções e monumentos (como colunas de jaspe) antecederam as narrativas do Eldorado ${ }^{15}$.

Desta maneira, a ilha, símbolo por excelência do isolamento, é "um lugar onde o maravilhoso existe por si mesmo fora das leis comuns" (DELUMEAU, 1995, p. 120) oposto ao universo fechado dos continentes. Ou seja, nas ilhas o homem é regido por um tempo e um espaço diferenciado do normal, um local onde o fantástico está sempre presente. O simbolismo que envolve esse local pode ser percebido mesmo nos mitos autóctones, como a procura dos índios brasileiros pelo seu Paraíso, que também estaria localizado em uma ilha fabulosa (SCHADEN, 1954, p. 185). Esse fato reforçou ainda mais os elementos imaginários europeus, quando do contato com as populações originais da América. Pode-se realizar do mesmo modo uma comparação do Eldorado com outra cidade fantástica americana, Cibola, derivada diretamente da matriz das ilhas paradisíacas $^{16}$.

Além da localização geográfica, também os detalhes arquitetônicos da narrativa de Martinez expressaram símbolos de longa duração. Um dos mais fan-

15. Outras seqüências do Amadís também influenciaram os conquistadores com seus locais fantásticos: o Palmerin de Oliva (1511) com a sua fonte da Juventude (publicada dois anos antes da expedição de Ponce de Leon ao fabulosos local), as Sergas de Esplandián (1515-1520) com o Reino das Amazonas da Califórnia (que impressionou Cortez, originando a denominação geográfica). (HOLLANDA, 1985, p. 19-20; PRATT, 1967, p.454-470).

16. A cidade imaginária de Cibola foi procurada pelos espanhóis de 1530 a 1540 no México. Teria sido fundamentada em tásticos, os leões presos às torres do palácio, são uma alegoria do poder. Em 1541, o padre Gaspar de Carvajal teria encontrado numa aldeia, a reprodução em relevo da cidade das amazonas que continha: "Dos torres muy altas de cabo con sus ventanas, y cada torre tenía una puerta frontera la una de la otra, y a cada puerta estaban dos colunas, y toda esta obra ya dicha estaba cargada sobre dos leones muy feroces, que miraban hacia atrás" (CARVAJAL, 1955, p. 86).

Não tendo equivalência na arquitetura indígena americana, o detalhe dos leões eram geralmente associados com o ouro e o sol, mesmo no simbolismo cristão medieval. Várias civilizações antigas construíam leões na entrada de palácios e fortalezas, como as famosas "Porta dos Leões" de Hatusa (Turquia) e em Micenas (Grécia). Também muito constante na heráldica européia, a inclusão desse símbolo animal confirma a necessidade do imaginário em buscar referências no desconhecido, expressando o poder pela arquitetura tipicamente européia.

Por sua vez, os outros elementos arquitetônicos como as colunas - também fazem parte de uma tradicional simbologia ocidental. Na cabala judaica e no ocultismo medieval, os pilares e colunas dos templos e palácios geralmente representavam a estabilidade eterna e o vão entre estas a entrada para a eternidade. Particularmente a coluna dupla aludia ao templo de Salomão, com suas Jaquim e Baez, também alegorias

uma série de mitos indígenas, chamados de Chicomoztot. As casas de Cibola seriam, segundo os espanhóis, construídas em pedras preciosas (GANDIA, op.cit. p. 65). Os sucessivos fracassos exploratórios originaram em regiões próximas outras cidades imaginárias, Axa e Quivira (no atual estado de Kansas), com torres resplandecentes e luminosas (GOMARA, op.cit. p.358). Outros locais fantasiosos na América, influenciados pelo mito medieval das Sete Cidades foram as Sete ilhas das Pérolas na Bacia do Prata (mencionado por Oertel em 1574 no Theatrum) e as Sete Cidades do Piauí. (LANGER, 1996, p.111-115). 
das corporações de ofício e da posterior Maçonaria. Estas continham em seu epitel uma lua, tal qual a descrita por Martinez no palácio do Eldorado, que também são muito comuns na arquitetura árabe (FERGUSSON, 1976, p. 98).

Seguindo a narrativa, após penetrar pelas colunas do palácio de Manoa, já no seu interior, percorria-se um quadrado plantado de árvores, regado por uma fonte com quatro tubos de ouro. Nos mosteiros e abadias medievais, os jardins quadriláteros com fonte central tinham relação com o simbolismo do número quatro: os elementos da matéria, os quatro evangelistas, os pontos cardeais e, principalmente, as letras do nome de Adão e os quatro rios do paraíso. Uma alusão, desta forma, ao jardim do Éden, o símbolo central da nostalgia dos tempos primordiais no imaginário medieval. Aliás, liga-se à própria etimologia do termo: Paradisus (Vulgata), Paradeisos (grego), derivados do persa Piridaeta, que significa jardim (FRANCO JUNIOR, 1992, p. 115). A existência desse jardim no centro do palácio também pode ser explicada pela ambigüidade da visão paradisíaca no Ocidente. Inicialmente o sonho coletivo do paraíso cristão (no Gênesis) estava baseado na imagem do Éden, o jardim idílico que alimentou as tradições dos lugares naturais e das ilhas perdidas. Já no Apocalipse, esta imagem se converteu em uma cidade, a Jerusalém Celeste, um referencial fantástico desta cidade histórica, reflexo da civilização urbana greco-romana ${ }^{17}$. Durante a Idade Mé-

17. As representações da cidade de Jerusalém concentramse em duas imagens tradicionais. Até o século VII, com inspirações orientais temos a denominada Jerusalém Escatológica, na qual se concebia que este centro histórico, no final dos tempos seria fértil e muito rico, socorrendo todo o mundo civilizado desta época. Após o século X, temos a Jerusalém Celeste, inspirada em Constantinopla, e que seria a equivalente no Paraíso desta cidade real. (PANTAGLEAN, 1994, p.461). dia, ocorreu um choque entre essas duas concepções imaginárias, exemplificado por Le Goff: "numa versão do Apocalipse de São Paulo vê-se o Paraíso-jardim absorver o Paraíso-cidade e os quatro centros deste paraíso provém do interior das paredes da cidade paradisíaca” (LE GOFF, 1984, p. 441). Mas na narrativa do Eldorado, ocorre a unificação dessas imagens: sua localização em meio à floresta tropical, a imagem da ilha no lago salgado, sua arquitetura oriental (inspirada em Jerusalém e Constantinopla), e por fim o jardim em seu interior.

Johannes Martinez ainda descreveu no interior do palácio um sol de ouro sobre um altar de prata diante do qual brilhavam quatros lâmpadas eternamente. Desde a Grécia antiga, existem relatos sobre misteriosas lâmpadas que nunca apagavam. Os romanos, segundo a tradição, fabricavam lâmpadas sepulcrais que se mantinham acesas por muitos anos através da oleosidade do ouro. Na Idade Média, Santo Agostinho referia-se a lâmpadas eternas existentes no templo de Vênus, que para ele simbolizavam a imortalidade do espírito (FERGUSSON, 1976, p.104-106). Assim, a referência destas lâmpadas no Eldorado, reafirma sua identificação com o Paraíso Perdido, a uma condição humana primordial, perpetuada por fantásticos locais inacessíveis.

\section{Maravilhoso e poder:}

\section{o Eldorado de Walter Raleigh}

Apesar da influência do manuscrito de Martinez, o relato mais famoso da cidade dourada foi publicado em 1596 na Inglaterra (The discoverie of the large, rich and beautiful empire of guiana, with a relation of the great and golden city of Manoa), pelo corsário Walter Raleigh, após suas buscas infrutíferas ao fabuloso local no norte da América do Sul. Seu autor não chegou a visitar a referida cidade, descrevendo em detalhes as populações indígenas que a delimitavam, tributárias do império das Guianas, muito 
poderoso "y adornado con tantas ciudades, villas, templos y tesoros" (RALEIGH, 1980, p. 65). Walter Raleigh acentuou a relação Peru-Eldorado, ao considerar o governante como descendente direto dos incas, que "está gobernado por las misma leyes, y el imperador y la gente observan la misma religion, y la misma forma y política de gobierno como se usaban en Peru" (RALEIGH, 1980, p. 66). O corsário britânico teve uma grande influência dos relatos de Jean de Mandeville, tanto na forma de narração quanto nos temas descritos. Ao contrário de Johannes Martinez, não afirmou que esteve na cidade em questão, mas que obteve informações fidedignas e confiáveis, de habitantes da região. Um procedimento que manteve também com as descrições dos descabeçados e das Amazonas, tal como Mandeville (ao obter informações de terceiros), o que de certa maneira, explicaria a enorme popularidade de seu relato. Por intermédio da narrativa de sir Walter Raleigh, esses personagens tornaram-se conhecidos no Velho Mundo, apesar de acéfalos constarem no Mappae Mundi de Piri Reis em 1513 e das Amazonas serem descritas por inúmeros relatos sobre o Novo Mundo.

Walter Raleigh conservou a cidade das amazonas em uma ilha, que teria "gran cuantidad de planchas de oro (chaguacas) e una classe de piedras verdes, que los espanoles llaman piedras de yade" (RALEIGH, 1980, p. 88). Em outra região, descreveu os Tivitiva, indígenas que construíam cidades em árvores e os Epuremeyo, que mantiveram uma grande cidade chamada Macureguary, em uma montanha. Porém a mais surpreendente descrição é a referente aos descabeçados, também habitantes de uma ilha: "son chamados Ewaipanoma, se informa que tienem los ojos en los hombros, y la boca en la mitad del pecho, y que una gran cola de pelo les crece hacia atras entre los hombros" (RALEIGH, 1980, p.161). A associação entre acéfalos e tesouros ocultos em terras exóticas também pode ser vislumbrada com o mapa-mundi de Leardo (1448). Na África misteriosa, concebida pelo cartógrafo, esses personagens habitam um país com montanhas de ouro. Sendo a narrativa de Raleigh apenas a conservação dessa associação no imaginário geográfico: os acéfalos funcionam como símbolos de guarnecimento das riquezas fabulosas, conferindo ao mesmo tempo exotismo e horror em suas imagens. Todos esses povos e cidades descritas, para Walter Raleigh, seriam tributários e súditos da capital do império das Guianas, Manoa, localizada em uma ilha ao centro do lago Parimá. Deste lago "y en muchos otros rios, ellos recogniam granos de oro perfectos, y en pedazos tan grandes como piedras pequenas" (RALEIGH, 1980, p. 177). Com Walter Raleigh vemos desenvolvida a forma final do Eldorado: o império que abrange toda a região norte do Amazonas. A matriz objetiva dessa representação foram os tradicionais reinos fantásticos do Ocidente, cujos mais famosos exemplos, os reinos de Prestes João e Ophir, em sua versões clássicas, estão também situados em ilhas e cercados de elementos fantásticos e maravilhosos.

Soberano cristão supostamente descendente dos Reis Magos, Prestes João e seu reino inicialmente eram localizados na Ásia (por volta de 1165), e a partir de 1480, os portugueses afirmaram ser na África. Símbolo do imperador universal, pois como o Eldorado, ultrapassaria todos os soberanos do mundo em riqueza e poder. Sua extrema mobilidade geográfica tem similariedades com as cidades douradas da América do Sul (são sucessivamente transferidas da Colômbia para a Venezuela, Guianas, Amazonas, Bolívia, Paraguai, Mato Grosso e outras regiões). Outra aproximação é a descrição do palácio-capital, construído sobre alicerces feitos de pedras preciosas, muros de ouro, grades e tetos de cristal. O relato mais famoso deste mirífico reino surgiu em 1357, com o conhecido Voiage de sir John Mandeville. Nele, encontramos um recolhimento de 
todas as lendas existentes neste período na Ásia, como as amazonas, os acéfalos, fonte da juventude, ilhas paradisíacas, animais bizarros e exóticos, regiões infernais, cidades fantásticas (DELUMEAU, 1995, p. 103-106) ou seja, todas as matrizes imaginárias do maravilhoso americano.

E o reino de Ophir, descrito pela Bíblia, seria o local de onde Salomão e o rei de Tiro mandavam vir suas maravilhas e riquezas em ouro, prata, marfim e pedras preciosas. De localização imprecisa, alguns autores clássicos o situaram em locais diferentes: Ptolomeu (Málaca), Hartenius (Oriente), D. Anville (Índias Orientais), e diversos outros na Etiópia. Cristovão Colombo em retorno à Europa, também acreditava ter descoberto Ophir em uma ilha das Antilhas, iniciando a relação do Novo Mundo com temáticas do fantástico ocidental. Além da imensa fortuna, esse reino também era conhecido pela justiça e benevolência de seus governantes (MANGUEL, 1987, p. 278). O espanhol Arius Montanus, o famoso autor da Bíblia poliglota, publicou o mapa mundi Pars Orbis em 1571 (Antuérpia). Nele a cidade de Ophir foi localizada na América do Sul, representada ao sul do rio Maranõn (Colômbia) ${ }^{18}$.

No livro de Walter Raleigh, a descrição da cidade de Manoa foi omitida, permanecendo apenas a das regiões circundantes, o que também confere uma certa aura de mistério. Que longe de desacreditá-la aumentou ainda mais sua popularidade e fama. Como essa inexistência objetiva de descrição se tornou o mais famoso relato do Eldorado? A imagem do local como cidade é implícita, pela

18. Arius Montanus foi influenciado, através de entrevistas em 1566-1567, com o conquistador espanhol Jimenez de Quesada em Santa Fé. Quesada havia explorado em 1537 a região da Colômbia em busca do Eldorado: encontrou o lago Guatavita, da qual retirou grande quantidade de ouro pré-colombiano (GIL, 1989, p.300) referência como capital do império, e as descrições das imensas riquezas tornam-no obrigatoriamente uma região desenvolvida e civilizada: uma urbe aos moldes europeus. A incerteza é um dos grandes estruturadores do imaginário do maravilhoso, que lhe permite sua longevidade na mentalidade pouco objetiva e empírica deste período. Justamente, essa ausência permitiu ao imaginário projetar modelos urbanos coletivos, pois cada intérprete do texto de Walter Raleigh confeccionou uma imagem específica de cidade. Isso foi perceptível a partir do sucesso da publicação do livro de Raleigh, onde o mito dourado provocou uma verdadeira efervescência no imaginário coletivo. Iniciam-se diversas ilustrações sobre a região amazônica, onde percebem-se diversas apropriações simbólicas, compensando novamente a falta de conhecimento sobre essas desconhecidas paragens.

A primeira representação iconográfica da cidade do Eldorado foi realizada por Antônio de Berrio e Walter Raleigh em 1595 (um anos antes da publicação de seu livro, durante a expedição ao Orenoco), e incluída na obra Travels, de Levinus Hulsius em 1599. Trata-se de um mapa onde representou-se um grande lago (com a inscrição The lake of Manoa $)^{19}$ de formato irregular, com inúmeros afluentes (num total de 33 rios) e ilhas de variados tamanhos. A cidade do Eldorado é situada na esquerda do lago e comparada com outras cidades do mapa ${ }^{20}$ seu tamanho é muito destacado: em forma retangular, com diversas torres cônicas e portões, lembrando um cas-

19. O lago de Parimá já havia sido representado anteriormente pela cartografia: em 1568 no mapa Portulan, de Fernando Vaz Dourado, um lago aparece sobre o Orenoco, porém sem denominação (ALÉS \& POUYLLAU, 1992, p.297).

20. O rio abaixo do lago Parimá apresenta a ilustração de 15 cidades - devido ao escasso tempo de ocupação dessa região, todas devem se também cidades imaginárias. 
telo medieval. Na mesma obra em que foi publicado esse mapa, surge outra representação desta cidade fantástica.

De autor anônimo, a ilustração tornou-se a mais famosa do fantasioso local, recebendo a denominação Manoa del Dorado, adotada por toda a posterior cartografia. A cidade é situada acima de uma grande lagoa (com o epíteto Lacus Salsus Parime), onde navegam dois grandes barcos a vela. Na margem esquerda do lago, diversas pessoas transportam mercadorias, canoas e carroças entre esta lagoa e um rio no canto superior (denominado Elsekebe F). Esse rio - o Essequibo - é o maior rio da atual Guiana Inglesa, e confirma definitivamente a localização do Eldorado neste local. Ou seja, de uma região de possessões espanholas (Colômbia, Venezuela), a cidade dourada transfere-se para domínios britânicos (apesar da maior parte do lago estar representada dentro da Amazônia portuguesa). Os dois veleiros ilustrados apresentam características tipicamente mediterrâneas. A vela é do tipo latino (alla trina - de forma triangular) presa a uma larga haste, com dois mastros. Tanto a popa quanto a parte de frente das embarcações possuem forma de gancho, característica de navios de origem árabe e utilizados na Europa durante os séculos XV e XVI (GOLDSMITH-CARTER, 1969, p.20).

A cidade do Eldorado é representada em volta de uma montanha, com duas grandes colunas circulares justapostas à entrada. Apresentando grande quantidade de torres com pináculos, casas, muralhas, aquedutos, minaretes espiralados, numa ampla fu-

${ }^{21}$ A similaridade da ilustração do Eldorado com a cidade de Constantinopla, pode ser observada em uma planta efetuada em 1420 pelo florentino Cristoforo Buondelmonti: toda a grande área de Constantinopla é reduzida e compactada entre as muralhas exteriores, reforçando o caráter de cidade-ilha e destacando os edifícios religiosos. são entre templo-cidade-fortaleza. A comparação com o modelo arquitetônico de Constantinopla é inevitável. A cidade apresentava em seu planejamento a seguinte ordem. Na extrema esquerda situavamse a coluna de Godos, a Igreja de Santa Sofia e o Palácio Sagrado - grandes construções religiosas que se destacavam pela altura e imponência no plano geral (RUNCIMAN, 1977, p. 146-147). A ilustração do Eldorado apresenta similariedades em forma e planejamento. O centro de Constantinopla era ocupado pelo aqueduto de Valens - no Eldorado o centro é preenchido por 3 retângulos simétricos com ranhuras inferiores, um óbvia representação estilizada de aqueduto ${ }^{21}$. A maior característica urbana da antiga Bizâncio é a localização circular ao mar de Propântide - no Eldorado é substituído pelo lago salgado do Parimá. Que ressalta no modelo imaginário como uma cidade-ilha. Desta forma, situada entre a confluência de duas civilizações (a oriental e a ocidental), o complexo urbano de Constantinopla serviu de modelo para cidade ideal durante muitos séculos. A arte européia acabou por perpetuar esse modelo imaginário, assim como a cartografia após o século XVII.

No mesmo ano de publicação das mencionadas representações do Eldorado (1599), surgiu o mapa Tabula Geographica de Theodoro De Bry, que acompanhou a tradução latina do livro de Raleigh ${ }^{22}$. Em termos geográficos, representaram até metade do

22 (Conf. ALÉS \& POUYLLAU, op.cit. p.297). Ainda em 1599 surgiu o mapa Niewe Caerte, de Jodocus Hondius: uma edição totalmente similar a de Theodoro De Bry. Em um epíteto central, informa que o lago Parimé possui a extensão de 200 léguas - um tamanho fabuloso para os padrões do período. O lago é cercado por uma extensa cadeia montanhosa e seu contorno é acentuado por linhas mais escuras. O desenho da cidade de Manoa, situado próximo a uma ilha, novamente recorda um castelo feudal com três torres escalonadas. 
século XVII o conhecimento mais apurado da realidade física e natural dessa região ${ }^{23}$. A carta de De Bry apresentava praticamente todos os detalhes mencionados por Raleigh em sua obra, destacando o imenso lago Parimá cortado pela linha do Equador.

É evidente que tanto a obra de Walter Raleigh, quanto a carta de De Bry e Hondius possuíam finalidades específicas de demonstrar familiaridade do europeu perante essa região geográfica, com claras intenções colonialistas pela Inglaterra e demais países europeus. Juntos, deram um extraordinário impulso para a difusão do mito do Eldorado. Os mapas cartográficos e os atlas não são apenas reveladores das concepções da realidade físico-geográfica de cada época, mas também eficazes instrumentos de amplificação das mesmas - popularizando mitos e fantasias sem correspondência com o real (TUCCI, 1985, p. 40-44).

As cidades imaginárias sul-americanas sobreviveram no pensamento erudito até meados do século XVIII, quando as novas fronteiras foram desbravadas pelos modernos exploradores, iniciando sua contestação científica. Porém, em sua grande maioria, transformaram-se através do folclore e das tradições, nas cidades perdidas e encantadas mantidas pelo imaginário popular até nossos dias (LANGER, 1996, p. 40-44). Afinal, o que seria do homem sem seus sonhos e fantasias?

23. A partir de sucessivas explorações, iniciaram-se as reformulações do mito dourado (ainda no séc. XVI): sua existência só foi possível manifestando-se em outros locais ainda pouco conhecidos. Dentre as mais famosas cidades vinculadas ao Eldorado, temos o Paititi (Peru) e o Gran Moxo (Paraguai e Mato Grosso). Outras cidades imaginárias sul-americanas foram: Ciudad de Los Césares (Chile e Argentina), Reino do Rei Branco (Prata), Waipite, Mairubi, Enim, Ambaya, Telan, Yunculo, Conlara, Ruparupa, Picora, Mojos, Trapalanda, Linlín, Tierra dos Musus, Los Caracaraes, Trapalana, Tierra de los Chunchos, Chunguri, Zenú, Meta, Macatoa, Candiré, Niawa, Dodoiba, Supayurca. (GANDIA, op.cit., p. 05-281).

\section{Conclusão: um mito de familiaridade simbólica}

Uma avaliação de todo o impacto e importância das cidades imaginárias durante a conquista e colonização da América se revela complexa e limitada. Não podemos esquecer que todas essas simbolizações e imagens estavam estreitamente relacionadas ao contexto mental predominante na época - a maioria dos indivíduos acreditavam na veracidade dessas representações - portanto, vinculada a todas as instituições (políticas, sociais e econômicas). Mesmo que tenham sido fundamentadas em tradições indígenas ${ }^{24}$, somente o fato de terem sido nomeadas pelos espanhóis (como Cibola e o Eldorado) indica um caráter acentuadamente eurocêntrico e conquistador. Não se procurou compreender a realidade autóctone, mas sim superá-la e mesmo adaptá-la às necessidades européias. Esse confiscamento da realidade americana durante o início da história moderna - o exemplo máximo foi Colombo, como percebe Stephen GREENBLATT (1996) - pode ser percebido na origem da tradicional representação do Eldorado: os europeus afirmaram compreender as descrições indígenas, criando assim o mito. O que ocorreu, porém, foi uma adaptação improvisada (desconhecia-se a maioria dos dialetos da Amazônia) dos supostos diálogos - a conquista também está presente na troca de palavras. A formação do mito confirmou essa relação. Projetando modelos tipicamente europeus, as imagens de cidades douradas desvincularam-se de qualquer elemento autóctone. Outro fator, presente até nossos dias, foi fundamental para a difusão e popularidade dessa imagens. Em regiões desconhecidas e temerárias, o mito fun-

24. Seria fundamental para uma melhor compreensão das cidades imaginárias americanas, o estudo do envolvimento da mitologia e das culturas indígenas em sua formulação - o que no presente momento encontra-se dificultado pela inexistência de pesquisas e fontes acessíveis. 
cionou como uma espécie de orientador de elementos familiares, facilitando o povoamento e a colonização. O seu enfraquecimento no século XVIII explica-se pelo sucesso da ciência nesse contexto: aumentando as áreas de expansão do conhecimento geográfico e dos centros populacionais, o maravilhoso (importante elemento perpetuador do mito) é restringido a escassas regiões. Um fator negligenciado, mas também fundamental, foi a perpetuação das cidades fantásticas pelo folclore popular, o que ocasionou ainda maior indiferença pelos intelectuais, pois as superstições eram consideradas sintomas de inferioridade du-

\section{Bibliografia}

AINSA, Fernando. "De la Edad de Oro a Eldorado". Revista Universidade de Antioquia. Medellin, julho de 1986.

ALÉS, Catherine \& POUYLLAU, Michel. "La conquete de l'inutile: les géographies imaginaires de l'Eldorado". L'Homme. Paris, n.122-124, 1992.

BACZO, Bronislaw. "Imaginação social". Enciclopédia Einauldi. Lisboa, Imprensa Nacional, 1984, p.308.

CARVAJAL, Gaspar de. Relación del nuevo descubrimiento del famoso rio Grande de las Amazonas (1541-1542). México, Fondo de Cultura Econômica, 1955.

CASTORIADIS, Cornelius. A instituição imaginária da sociedade. (Trad.). São Paulo, Paz e Terra, 1982.

DELUMEAU, Jean. Uma história do Paraíso (trad.). Lisboa, Terramar, 1995.

FERGUSSON, John. Encyclopaedia of misticism. Londres, Thames and Hudson, 1976.

FERNANDO PÉREZ, Pablo. "El cacicazgo de Guatavita”. Boletin del Museo del Oro. Bogotá, n.26, janeiro de 1990.

FRANCO JR., Hilário. As utopias medievais. São Paulo, Brasiliense, 1992.

GANDIA, Enrique. História crítica de los mitos de la conquista americana. Buenos Aires: Juan Roldan, 1929.

GIL, Juan. Mitos e utopias del descubrimiento. Vol.III: "El Dorado". Madrid, Alianza Editorial, 1989.

GIRARDET, Raoul. Mitos e mitologias políticas (trad.). São Paulo, Cia das Letras, 1987.

GIUCCI, Guilherme. Os viajantes do maravilhoso (trad.). São Paulo, Companhia das Letras, 1992.

GOLDSMITH-CARTER, George. Velas e veleiros (trad.). São rante a época das luzes. A relação fundamental para se compreender o mito das cidades fantásticas coloniais - incerteza, repetição e analogia de elementos simbólicos familiares sobre o desconhecido - representa uma das facetas mais extraordinárias da capacidade humana, de imaginar e conceber imagens que possam libertá-lo de sua prisão que constitui o espaço físico. O homem, em sua eterna busca pelo ilimitado, acabou criando mitos que respondem ao seu desejo de poder e conquista, características inseparáveis tanto das cidades fantásticas como da própria sociedade moderna.

Paulo, Melhoramentos, 1969.

GOMARA, Lopes de. História general de las Índias (primeira edição em 1552). Barcelona, Ed. Lebo, 1965.

GRAN DICTIONNAIRE DU XIX SIÉCLE. Eldorado. Paris, Ed. Pierre Larousse, 1871.

GREENBLATT, Stephen. Possessões maravilhosas (trad.). São Paulo, Edusp, 1996.

GRIMAL, Pierre. Diccionario de la mitologia griega y romana (trad.). Barcelona, Ed. Lebo, 1965.

HOLLANDA, Sérgio Buarque de Hollanda. A visão do Paraíso. São Paulo, Ed. Nacional, 1985.

HUBER, Sigfried. O segredo dos incas (trad.). Belo Horizonte, Itatiaia, 1961.

LANCIANNI, Giulia. "O maravilhoso como critério de diferenciação entre sistemas culturais". Revista Brasileira de História. São Paulo, n.21.

LANGER, Johnni. Arqueologia do irreal: as cidades imaginárias do Brasil. Dissertação de mestrado apresentada ao dep. de História da UFPR. Curitiba, agosto de 1996.

LAS CASAS, Bartolomé de. História de las Índias (século XVI). México, Fondo de Cultura Econômica, 1951.

LE GOFF, Jacques. "Escatologia”. In: Enciclopédia Einauldi. Lisboa, Imprensa Nacional, 1984.

LE GOFF, Jacques. O maravilhoso e o cotidiano medieval (trad.). Lisboa, Ed.70, 1985.

MANGUEL, Alberto (org.). The dictionary of imaginary places. New York, Harvest Book, 1987.

MARSON, Adalberto. "Colombo e o encanto do ouro". Humanidades. Brasília, vol.8, n.2, 1992. 
MEGGERS, Betty. América pré-histórica (trad.) São Paulo, Paz e Terra, 1985.

MELLO E SOUZA, Laura de. O diabo e a terra de Santa Cruz. São Paulo, Companhia das Letras, 1986.

NAVARRO, Tânia. "Os mitos da descoberta do Brasil". Humanidades. Brasília, UNB, vol.8, n.2, 1992.

NOUHAD, Dorita. "Eldorado". In: BRUNNEL, Pierre (org.). Dictionnaire des mythes litteraires. Paris, Ed. Nocher, 1988.

PANTAGLEAN, Evelyne. "La double terre sainte de Byzance". Annales: Paris, n.2, 1994.

PRATT, Angel Valbuena. Historia de la literatura espanola. Vol.II. Barcelona, Gustavo Gili, 1967.

RALEIGH, Walter. Las doradas colinas de Manoa (Orig. The Discoveries of the large, rich and beautiful empire of guiana...1596) (trad.). Caracas, Ediciones Centauro, 1980.
RAMOS PÉREZ, Demétrio. "El mito del Dorado no tiene un origen andino". In: Historica. Lima, vol.XIX, n.2, dez. 1995.

RAMOS PÉREZ, Demétrio. "El mito del Dorado no tiene un origen andino”. Historica. Lima, vol.XIX, n.2, dez. 1995

RAMOS PÉREZ, Demétrio. "Examen critico de las noticias sobre el mito del Dorado". Cultura Universitária, Caracas, n.41, jan. 1954, p.20-54.

RUNCIMAN, Steve. A civilização Bizantina (trad.). Rio de Janeiro, Zahar, 1977.

SALAS, Mariano Picon. De la conquista a la independencia. México, Fondo de Cultura Economica, 1967.

SCHADEN, Egon. "Aspectos fundamentais da cultura Guarani". Boletin da Universidade de São Paulo. São Paulo, n.188, 1954.

TUCCI, Ugo. "Atlas”. Enciclopédia Einauldi. Lisboa: Imprensa Nacional, 1985. 